BMJ Open Sport \& Exercise Medicine

\section{Ethical dilemmas and validity issues related to the use of new cooling technologies and early recognition of exertional heat illness in sport}

To cite: Muniz-Pardos B, Angeloudis K, Guppy FM, et al. Ethical dilemmas and validity issues related to the use of new cooling technologies and early recognition of exertional heat illness in sport. BMJ Open Sport \& Exercise Medicine 2021;7:e001041. doi:10.1136/ bmjsem-2021-001041

Accepted 31 March 2021
Check for updates

C Author(s) (or their employer(s)) 2021. Re-use permitted under CC BY-NC. No commercial re-use. See rights and permissions. Published by BMJ.

For numbered affiliations see end of article.

Correspondence to Dr Yannis P Pitsiladis; Y.Pitsiladis@Brighton.ac.uk

\section{ABSTRACT}

The Tokyo 2020 Olympic Games is expected to be among the hottest Games in modern history, increasing the chances for exertional heat stroke (EHS) incidence, especially in non-acclimatised athletes/workers/spectators. The urgent need to recognise EHS symptoms to protect all attendees' health has considerably accelerated research examining the most effective cooling strategies and the development of wearable cooling technology and realtime temperature monitoring. While these technological advances will aid the early identification of EHS cases, there are several potential ethical considerations for governing bodies and sports organisers. For example, the impact of recently developed cooling wearables on health and performance is unknown. Concerning improving athletic performance in a hot environment, there is uncertainty about this technology's availability to all athletes. Furthermore, the real potential to obtain realtime core temperature data will oblige medical teams to make crucial decisions around their athletes continuing their competitions or withdraw. Therefore, the aim of this review is (1) to summarise the practical applications of the most novel cooling strategies/technologies for both safety (of athletes, spectators and workers) and performance purposes, and (2) to inform of the opportunities offered by recent technological developments for the early recognition and diagnosis of EHS. These opportunities are presented alongside several ethical dilemmas that require sports governing bodies to react by regulating the validity of recent technologies and their availability to all.

\section{BACKGROUND}

While the Tokyo 2020 Olympics has been postponed to summer 2021, the environmental conditions are expected to be comparable or even more challenging than the conditions experienced during the last few years, ${ }^{1}$ with daily air temperatures exceeding $30^{\circ} \mathrm{C}$ and relative humidity levels above $70 \% .^{2}$ For example, during the summer of 2018 and

\section{Summary box}

\section{What is already known}

- Precooling and percooling strategies effectively minimise the impact of heat on athletic performance in numerous sports.

- Wearable technology is expanding worldwide with little external scientific validation.

- External and publicly available validity data are not a prerequisite for wearable technology to be used during competition.

What are the new findings

- The implementation of cooling wearables for health and performance purposes in sport should be regulated based on their effectiveness and availability.

- Real-time monitoring of physiological, biomechanical and biochemical data is a reality. Its application in large-scale sporting events will aid in the early recognition of exertional heat stroke in athletes, spectators, workers and all attendees at the Tokyo 2020 Olympics.

- Several ethical issues must be solved concerning cooling wearables utilisation and real-time monitoring so that both the athlete's physical integrity and sports integrity prevail.

2019, Tokyo suffered severe heatwaves that led to thousands of hospitalisations and a notable surge in victims of heat-related death nationwide. ${ }^{3}$ However, it is worth noting that temperatures during summer 2020 have been extraordinarily low compared with the previous 2 years (figure 1), which is an unexpectedly favourable trend that cannot be assured for the upcoming years. July and August are the warmest, most humid and wettest months in Tokyo, with noticeable convective shifts in early August, which bring more intense heat and humidity. ${ }^{4}$ Given that predictions point towards increases in 

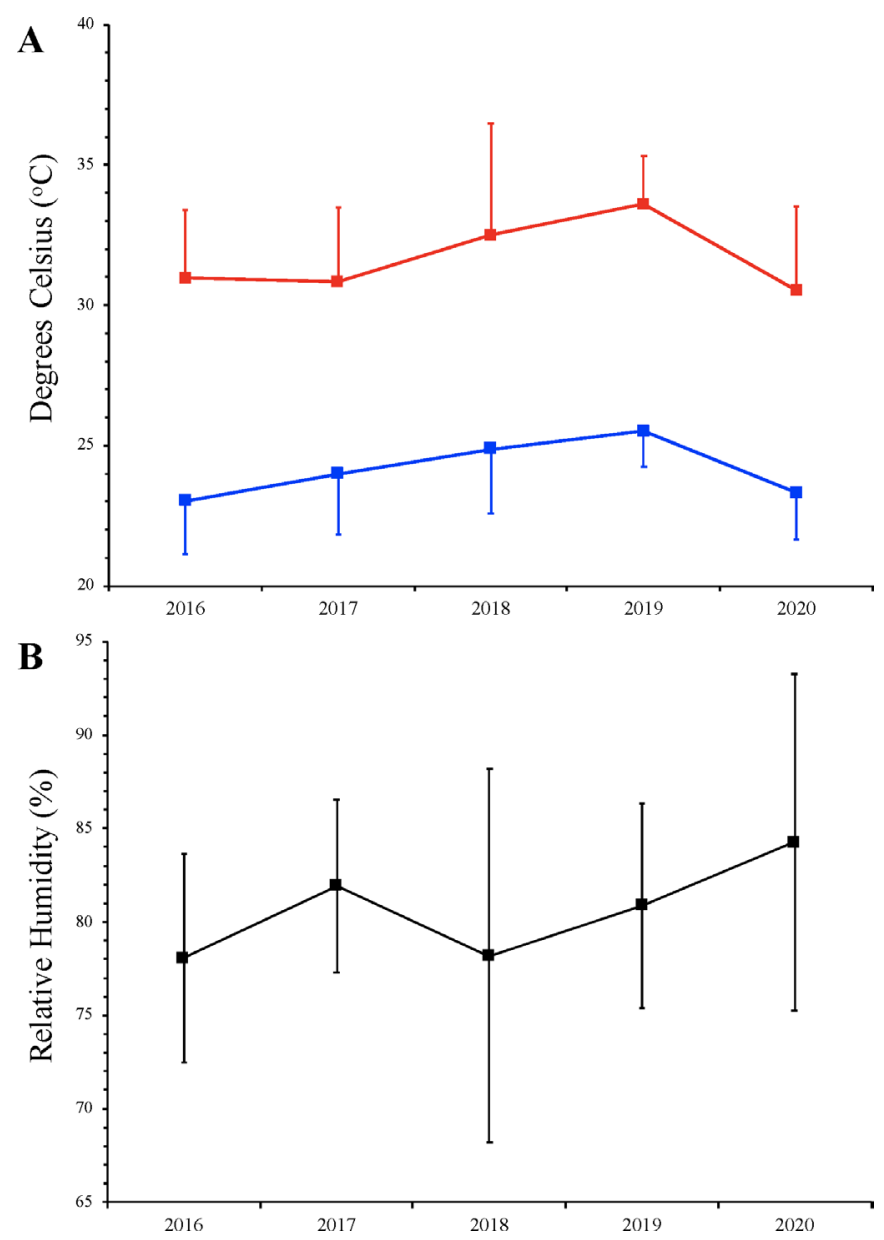

Figure 1 Minimum ( $A$; blue) and maximum ( $A$; red) daily air temperatures, and relative humidity $(\mathrm{B})$ during the Olympic competitive period (23 July to 8 August) from 2016 to 2020 in the metropolitan area of Tokyo (Japan). Data shown are mean $\pm S D$. Data from the Japanese Ministry of the Environment. ${ }^{56}$

the frequency and intensity of heatwaves worldwide in response to climate change, ${ }^{5}$ these conditions are also likely to become more prevalent in the future. Hosokawa et $a t^{6}$ used a 36-year (1980-2016) modelled climatological wet-bulb globe temperature (WBGT). This index integrates the influences of temperature, humidity, wind speed, sun angle and solar radiation that can affect heat stress to evaluate heat risk at the venues that will be hosting international sporting events (eg, Tokyo Olympics). These data revealed that the WBGT might exceed $30^{\circ} \mathrm{C}$ in $40 \%-50 \%$ of the late mornings and early afternoons of the scheduled days during the competition in Yokohama and Saitama, which illustrates the need for a change in organisational decision-making and rigorous event planning. ${ }^{6}$

The 1-year postponement of the Games caused by the COVID-19 pandemic provides sports governing bodies, scientists, sporting teams and other stakeholders with more time to plan preventive strategies and implement new technologies to protect the health of all participants (ie, athletes, workers, officials, spectators) at the Tokyo
2020 Games. Similar to the numbers recorded for Rio de Janeiro Olympics 2016, around 11000 athletes are expected to participate in Tokyo $2020 .^{7}$ Although the number of spectators will be reduced since Tokyo Olympics will not accept foreign visitors due to the COVID-19 pandemic, local non-acclimatised spectators will be at high risk of heat stress. ${ }^{8-10}$ Therefore, the aim of the present review is (1) to summarise the practical applications of the most novel cooling strategies/technologies for both safety (of athletes, spectators and workers) and performance purposes, and (2) to inform of the opportunities offered by recent technological developments for the early recognition and diagnosis of exertional heat stroke (EHS). These opportunities are presented together with several ethical dilemmas that must be considered by sports governing bodies and sporting event organisers.

\section{COOLING STRATEGIES TO OPTIMISE SAFETY AND PERFORMANCE IN THE HEAT}

From a medical perspective, EHS is the most severe form of exertional heat illness (EHI) and should be considered when an athlete struggles or collapses during exercise in the heat. The two key diagnostic criteria used are a rectal/ core temperature $>40^{\circ} \mathrm{C}$ and central nervous system dysfunction (eg, coma, altered consciousness, confusion, combativeness, agitation, unresponsiveness). ${ }^{11}$ When EHS is present, cold water immersion (CWI) should be undertaken as soon as possible and on-site if medical personnel are available following the cool first, transport second approach. $^{12}$ Casa and colleagues ${ }^{13}$ showed the cooling effectiveness of 25 different cooling strategies (including ice packs, hand cooling or tap water splashing), with CWI showing the greatest cooling rates (especially ice water immersion at $2^{\circ} \mathrm{C}$, with a cooling rate of $0.35^{\circ} \mathrm{C} / \mathrm{min}$ ). However, Casa et $a l^{13}$ noted that when immediate CWI is not possible, medical staff should consider using other interventions such as placing cold/wet towels over the entire body, cold showers, or dousing athletes with cold water from a hose. Notably, workers or spectators are also at risk of suffering EHI even with a relatively low level of physical activity, such as simply walking between venues in severely hot environmental conditions. ${ }^{1014}$ Moreover, for most outdoor sports, spectators are expected to be standing or sitting in crowded, often unshaded areas, with large crowds causing decreased airflow and higher temperatures due to metabolic heat production. ${ }^{9}$ This situation may hinder effective identification and intervention, given that symptoms may go unobserved. The estimated thermal discomfort to be experienced by spectators during the original marathon route (in Tokyo) ${ }^{10}$ suggests authorities should establish preventive strategies such as providing artificial ventilation with fans in congested areas, providing adequate free water to spectators, or creating free 'Cool Spot' signs along the courses so that spectators can seek cooling to mitigate the negative effects of the heat. ${ }^{10} \mathrm{~A}$ rapid intervention for either athletes or non-athletes in case of EHS will be crucial, considering that individuals suffering EHS will likely have 
no detrimental consequences if their core temperature decreases to $<40^{\circ} \mathrm{C}$ within $30 \mathrm{~min}$ of collapse, but may suffer permanent disabilities or even death if treatment is postponed beyond this time frame. ${ }^{15}$

From a performance perspective, cooling strategies applied before (ie, precooling) and during (ie, percooling) exercise in the heat have been shown to attenuate the associated decline in athletic performance ${ }^{16}$ by reducing thermal strain and increasing heat storage capacity. ${ }^{17}$ The reduction of thermal strain has been shown to reduce both cardiovascular (eg, decrease in heart rate and cutaneous blood flow) and psychological stress (eg, perceptual responses) associated with exercise in the heat. ${ }^{18-20}$ Bongers and colleagues recently published an infographic ${ }^{21}$ updating their previous meta-analysis ${ }^{16}$ focused on the effectiveness of cooling strategies on athletic performance. This updated data set included 71 experiments and 697 moderately to well-trained participants and revealed improved exercise performance following both precooling $(4.7 \%)$ and percooling $(5.3 \%)$ methods compared with no cooling. This study suggested that the most effective precooling strategy is CWI, eliciting a $7.1 \%$ performance improvement, while wearing an ice or cooling vest was the best percooling strategy ( $11.9 \%$ performance improvement). Additionally, these authors found greater performance improvements for endurance exercise protocols $(6.4 \%)$ when compared with intermittent sprint exercise protocols $(3 \%) .{ }^{21}$ However, Arngrimsson and colleagues pointed out that CWI as a precooling method may not be feasible for athletes immediately before a competition. This would make warming up before the competition challenging. ${ }^{22}$ These authors demonstrated that wearing a cooling vest with ice packs during the warm-up elicited a $1.1 \%$ (ie, $13 \mathrm{~s}$ ) improvement over a $5 \mathrm{~km}$ time trial, which may be meaningful to those who compete in the elite level.

Notably, cooling methods must be adjusted and selected during training according to the athletes' comfort and tolerability to avoid undesirable thermal responses during the competition, such as shivering, ${ }^{12}{ }^{23}$ and optimising cooling at the individual level depending on the environmental characteristics and the athlete's response. Despite the substantial role of both precooling and percooling strategies to reduce core temperature and to improve exercise performance, during the 2015 World Athletics Championships in Beijing, only half of the athletes planned precooling strategies, with no athletes using percooling methods. ${ }^{24}$ However, during the 2019 World Athletics Championships in Doha, where the challenging environmental conditions obliged the organising body and technical teams to strengthen the preventive measures, $80 \%$ of the road race athletes used precooling strategies and $93 \%$ used percooling methods. ${ }^{25}$

\section{DEVELOPMENT OF PORTABLE COOLING TECHNOLOGIES}

Cooling methods and devices are not new, and previous research in military personnel and firefighters has examined the effectiveness of wearing different air-cooled garments, ${ }^{26-28}$ circulating liquid cooling garments ${ }^{27-29}$ and other passive cooling methods (eg, ice, gel, salt, wax, and so on) within vests/clothing. ${ }^{30-32}$ Most of these articles focused on thermal strain during prolonged, lowintensity exercise (eg, 3-hour walking at $3.5 \mathrm{~km} /$ hour $^{28}$ ) while wearing additional combat/protective clothing. While these articles have shown a significant alleviation of thermal strain (ie, decreased body temperature and reduced sweat rates), the direct application of these findings to sport-specific conditions (exercise intensity, clothing, exercise duration) may be inaccurate.

The use of cooling devices/wearables during exercise in athletes has not been extensively investigated in the past due to the associated logistic disadvantages and impracticalities during the competition (eg, excess of weight, skin irritation and issues with sporting regulation). ${ }^{33} 34$ Nonetheless, Bongers and colleagues highlighted that cooling during exercise increased exercise capacity by a factor of $7 \% .{ }^{16}$ Further research revealed that the use of cooling vests during exercise elicited a $20.4 \%$ improvement in cycling performance. ${ }^{35}$ However, the weight of cooling vests (ie, from 1 to $4.5 \mathrm{~kg}$ approximately ${ }^{2235}$ ) may negate their benefit in those sporting activities where increased body mass impairs performance (eg, endurance running). Alternative cooling garments to be used during exercise include neck, wrist and head cooling devices. ${ }^{36}$ Ruddock and colleagues recently performed a meta-analytical study focused on the effects of practical cooling methods (only those feasible to be used during competition) on heat strain and endurance performance. ${ }^{36}$ Cooling the neck during heat exposure seemed to enhance thermal comfort at rest and during exercise in two of the three existing studies. However, core temperature and performance were not modified. Accordingly, Schlicht and colleagues found negligible improvements of wrist cooling on core temperature during recovery from exercise-induced heat stress from wearing firefighting protective equipment. ${ }^{37}$ Further consideration and caution must be considered, bearing in mind that some of these garments seem to only create a perception of cooling without core temperature decrease. ${ }^{34}$

Several companies have created new cooling wearable technologies during the last year, with some of the most novel and promising summarised in table 1. However, their cooling effectiveness in safety/performance is currently unknown. A major electronics manufacturer has recently developed an air-conditioner to be placed in a pocket on the upper back that presumably allows the wearer to cool the local microenvironment on the body surface using a mobile application. ${ }^{38}$ However, further research is needed to determine this technology's true systemic effect, especially during exercise in the heat. Further, companies have developed neck coolers claiming that wet/cold towels may not be sufficiently effective for the challenging environmental conditions expected in Tokyo. ${ }^{39}$ Wrist coolers are also emerging. Some manufacturers claim that wearers perceive whole-body 
Table 1 Recent wearable technology designed to cool an individual in a hot environment during exercise

\begin{tabular}{ll}
\hline Technology & Description \\
\hline $\begin{array}{l}\text { Pocket air- } \\
\text { conditioners }\end{array}$ & $\begin{array}{l}\text { Wireless device that, when in contact with one's skin through a shirt, can potentially cool the nearby } \\
\text { skin area (eg, ref 38). }\end{array}$ \\
$\begin{array}{l}\text { Weck coolers } \\
\text { Coarable devices fitted on the shoulders of the individual and adapted around the neck. This wearable } \\
\text { cooling device has a thermal cooling plate that collects humid air and transforms it into cool air (eg, ref } \\
\text { 39). }\end{array}$ & $\begin{array}{l}\text { This bracelet-like wearable contains a thermostat and cools down or warms up at the press of a button } \\
\text { (eg, ref } 40) .\end{array}$ \\
Cooling fabrics and coolers & $\begin{array}{l}\text { This technology is claimed to pull moisture away from the skin and disperse it throughout the fabric } \\
\text { along channels on the thread surface. Moisture is moved away from one's skin and circulates } \\
\text { throughout the fabric while controlling the natural evaporation rate (eg, ref } 41) .\end{array}$ \\
\hline
\end{tabular}

These wearable technologies have been selected following an internet search and are not comprehensive.

cooling of a few degrees Celsius when submitted to the specific cooling protocols they recommend. ${ }^{40}$ Additionally, Yu et $a t^{11}$ have revealed the invention of a new type of wearable fabric containing thermoconductive, moisture-permeable and superhydrophobic nanofibrous membranes. While this promising technology exhibited an improved cooling performance and effective water repellence compared with conventional fabrics, its effect and applicability in reducing core temperature during exercise in hot environments are yet to be established. Of note, the validity and reliability assessments of the wearable technologies displayed in table 1 are either lacking or not publicly available.

\section{TECHNOLOGICAL DEVELOPMENT FOR HEATSTROKE RECOGNITION AND DIAGNOSIS}

The medical staff's primary challenge to optimise treatment of EHS is the early recognition of the condition. ${ }^{42}$ A common misconception is that all patients with EHS will have stopped sweating, have hot skin or be unconscious. However, none of these symptoms are required for a diagnosis of EHS. ${ }^{42}$ Previous case reports have identified that patients with EHS are likely to be awake, with cool and clammy skin, and sweat profusely. ${ }^{42}$ Belval and colleagues presented a basic algorithm for recognising EHS in which they include markers such as the assessment of central nervous system function, responsiveness or core temperature. ${ }^{42}$ However, the rapid assessment of these conditions may be challenging during competition, and the use of specific wearable devices may play a crucial role in the early identification of EHS symptoms.

The challenging environmental conditions expected in summer 2021 in Tokyo and the urgent need to recognise heat-related illness symptoms to protect all attendees' health have accelerated the development of wearable technology and real-time monitoring. Wearable devices (eg, ingestible core temperature pills ${ }^{43}$ ) able to monitor and transmit thermal stress in real time ${ }^{44}$ would permit the medical personnel and technical staff to intervene and prevent an athlete from suffering EHS. With this purpose in mind, a technological ecosystem (ie, an integrated system that involves dynamic interactions between different applications or wearables; figure 2) has been recently developed by a group of sports physiologists, engineers and experts in biomechanics ${ }^{45}$ that provides live feedback of land and air temperature, heart rate, core temperature and a range of physiological and biomechanical parameters facilitated through a Cloud-based portal. This technology allows the support/ medical team to view the data on a desktop, tablet or a smartphone in real time anywhere with internet access, for which internet use should be capitalised. Our group tested the effectiveness of this ecosystem during two pilot experiments in Iten (Kenya) and Seville (Spain) with elite athletes. ${ }^{4546}$ While the implementation of this technology (ie, early recognition through real-time core temperature monitoring followed by earlier cooling) may appear to be only applicable for the athletic population due to logistic or economic issues, this could also apply to all spectators and attendees. The organisers could be monitoring the core temperature of thousands of individuals at a big event (eg, Olympic Games) and alert those at risk of heat-related illnesses to urgently go to air-conditioned rooms or make use of specific (and effective) cooling wearables provided by the organisers.

\section{EFFECTIVENESS AND SPORT INTEGRITY ISSUES}

An important drawback of the rapid introduction of cooling wearable technologies (eg, table 1) is that they may be publicly available before their effectiveness has been scientifically demonstrated and before validity and reliability tests are published and accessible to all users. The lack of quality control procedures, recently discussed in a critical review, ${ }^{47}$ poses a real threat that some athletes could use this technology and potentially gain an unfair advantage, be that perceived or real, over their competitors if this validity/effectiveness information is not available to all-similar to the recent debate surrounding carbon fibre plate running shoes. ${ }^{48}$ Medical/technical teams should always rely on accurate and valid core temperature monitoring (eg, specific temperature capsule systems ${ }^{49}$ ) to avoid withdrawing an athlete from competition prematurely, potentially costing him the chance of winning an Olympic medal or, if using 


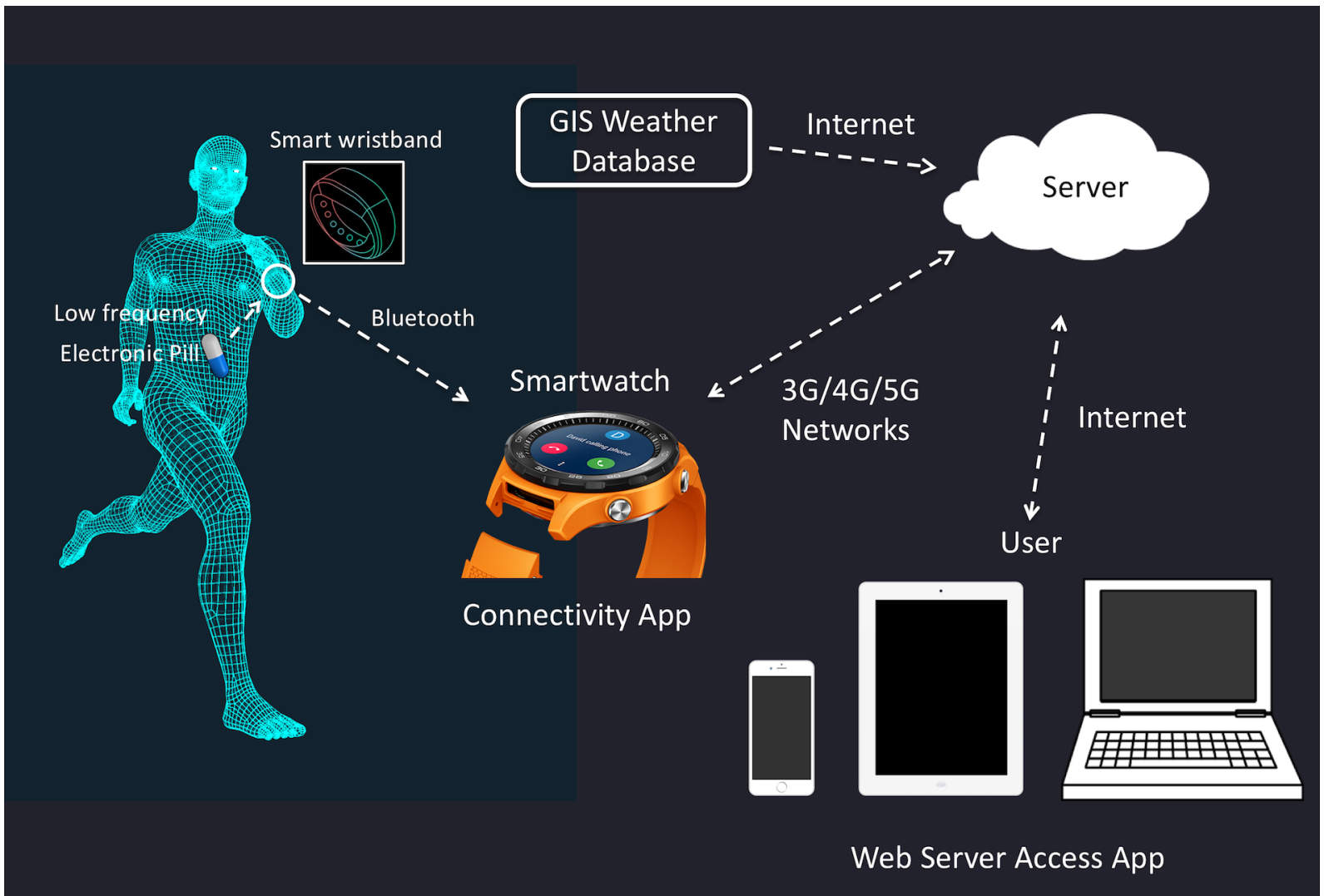

Figure 2 Smart activity and temperature monitor to enhance safety during sporting events with particular reference to athletes, officials and workforce at increased risk. Licence number: 4654951032268. App, application; GIS, geographic information system.

inaccurate/not validated methods, potentially exposing him to EHS and its life-changing consequences. Current technical regulation regarding the assistance allowed to the athlete, in the case of World Athletics, states that athletes are allowed to use 'any kind of personal safeguard (eg, bandage, tape, belt, support, wrist cooler, breathing aid, etc) for protection and/or medical purposes. The Referee, in conjunction with the Medical Delegate, shall have the authority to verify any case should the Referee judge that to be desirable' (Rule $6.4 .3) .{ }^{50}$ Nevertheless, this rule does not specifically state that the technology must be either scientifically tested or available to all to avoid an unfair performance advantage over other competitors. However, the IOC has prohibited using certain equipment during the Tokyo 2020 Olympics, including oxygen tanks and cylinders, hypoxic or hyperoxic tents/chambers and cryogenic chambers. ${ }^{51}$ The use of recent technological developments during Tokyo 2020 should also be regulated considering their effectiveness for health and performance purposes and considering further ethical issues discussed in the next paragraphs.

Two different potential issues are presented here: (1) the need for wearable technology to be submitted to quality testing procedures to scientifically demonstrate their effectiveness, validity and reliability, and (2) if a significant ergogenic aid is demonstrated, the need to assess whether this advantage is fair within sport and available to all athletes in competition. To address the first issue, the International Federation of Sports Medicine (FIMS) has decided to establish a central resource at a FIMS-accredited laboratory, located at the University of Zaragoza, Spain, to guide wearable technology providers to achieve quality control and data standardisation, with the cooling wearables described in table 1 already under validation. Similar international standard setting initiatives are widely used. For instance, the International Organization for Standardization provides standards for meteorological measurements so that users can use comparable and reliable data. This model applied to the standardisation of wearable technology would enable companies to have their validation tests performed and receive a FIMS certification and allow all athletes/ governing bodies to select the most appropriate/effective devices for their specific needs. Given that data about the effectiveness of a wearable would then be publicly available, governing bodies and competition organisers should exclusively accept those FIMS-certified devices as a guarantee that they have been through a validation process.

While we await the outcome of the effectiveness of cooling wearables, many ethical considerations need to be considered, such as the requirement that technological devices that can significantly impact on performance or health status be available to every athlete/technical team due to 'the spirit of the universality of athletics [sport in general]', as was recently described in the World Athletics 
Technical Rules. ${ }^{52}$ An additional major ethical dilemma athlete support teams will face if they can access real-time core temperature monitoring is related to their potential decision to withdraw their athlete/s from the competition if they are at risk of EHS. A hypothetical marathoner could be running with a core temperature of $41.8^{\circ} \mathrm{C}$ when there is only $1-2 \mathrm{~km}$ left to win a medal, as experienced by Scottish athlete Callum Hawkins at the 2018 Commonwealth Games. ${ }^{53}$ Therefore, the athlete support team must decide to either (1) withdraw the athlete from the race, although the athlete might not accept this decision, or (2) not intervene and let the athlete attempt to finish the race, potentially causing harm to the athlete's health. This is a new ethical dilemma that must be discussed and regulated since previously core temperature data could only be downloaded after an event and could not be used to prevent EHS. In a further hypothetical scenario, Callum Hawkins could be running the same marathon with a core temperature of $40.9^{\circ} \mathrm{C}$ (ie, just above the critical threshold for cell damage; $40.82^{\circ} \mathrm{C}^{15}$ ) and just $2-4 \mathrm{~km}$ left in the race $(6-12 \mathrm{~min}$ if the athlete is running at a pace of $3 \mathrm{~min} / \mathrm{km}$ ). The medical personnel would be ready to intervene within $30 \mathrm{~min}$ from this point. ${ }^{15}$ The core temperature data would aid the decisionmaking process in all scenarios (including a collapse below a core temperature of $40.9^{\circ} \mathrm{C}$ ). The individual core temperature that a heat-acclimatised athlete can reach and sustain without EHS symptoms would need to be determined to provide the athlete with adequate individual protection and do not overprotect/underprotect by taking drastic measures during the competition (ie, pull the athlete out unnecessarily or dangerously do not intervene). High individual core temperatures have been found in professional rugby players $\left(>39.5^{\circ} \mathrm{C}\right)$ and elite cyclists $\left(>40.5^{\circ} \mathrm{C}\right)$ without ill effects, ${ }^{54}{ }^{55}$ which illustrate the importance of understanding interindividual heat strain during exercise. Notley et $a l^{14}$ have recommended using real-time monitoring of multiple physiological and perceptual strain indices rather than solely rely on core temperature to avoid EHS in occupational workers. The concurrent monitoring of physiological, biomechanical and perceptual data will likely identify EHS symptoms more accurately. ${ }^{44}$ Finally, the data generated need consideration regarding the athlete's biophysical data ownership and the development of encryption technology to avoid competitors illegally accessing other athlete's data to gain a competitive advantage. Once these effectiveness and ethical considerations are resolved with more data and evidence-based recommendations, the appropriate implementation of wearable technology is likely to provide earlier identification of EHS symptoms allowing for the initiation of more active interventions and the provision of greater flexibility to ensure competitor safety, which are crucial approaches given the rapidly warming climate combined with the timing of many sporting events.
Author affiliations

${ }^{1}$ GENUD Research Group, Faculty of Health and Sport Sciences, University of Zaragoza, Zaragoza, Spain

${ }^{2}$ Centre for Stress and Age Related Disease, University of Brighton, Brighton, UK ${ }^{3}$ School of Pharmacy and Biomolecular Sciences, University of Brighton, Brighton, UK

${ }^{4}$ Faculty of Sport Sciences, Waseda University, Tokorozawa, Saitama, Japan ${ }^{5}$ Center for Medical Informatics, Yale School of Medicine, New Haven, Connecticut, USA

${ }^{6}$ Pain Research, Informatics, Multi-morbidities, and Education (PRIME), VA Connecticut Healthcare System, West haven, CT, USA

${ }^{7}$ Institute for Sports Medicine, Alpine Medicine and Health Tourism, Tirol Kliniken Innsbruck and UMIT Tirol, Hall, Austria

${ }^{8}$ Department of Geography, University of Georgia, Athens, Georgia, USA

${ }^{9}$ Marubeni Health Promotion Center, Tokyo, Japan

${ }^{10}$ Athlete Health and Performance Research Centre, Aspetar Qatar Orthopaedic and Sports Medicine Hospital, Doha, Qatar

${ }^{11}$ Korey Stringer Institute, University of Connecticut, Storrs, Connecticut, USA

${ }^{12}$ Centre for Exercise Sciences and Sports Medicine, FIMS Collaborating Centre of Sports Medicine, Rome, Italy

${ }^{13}$ International Federation of Sports Medicine (FIMS), Lausanne, Switzerland

${ }^{14}$ European Federation of Sports Medicine Associations (EFSMA), Lausanne, Switzerland

\section{Twitter Sebastien Racinais @ephysiol}

Contributors All authors have provided sufficient work to justify authorship and in line with the instructions to authors.

Funding The authors have not declared a specific grant for this research from any funding agency in the public, commercial or not-for-profit sectors.

Competing interests GIA is supported by a fellowship from the Office of Academic Affiliations at the US Veterans Health Administration.

\section{Patient consent for publication Not required}

Provenance and peer review Not commissioned; externally peer reviewed.

Open access This is an open access article distributed in accordance with the Creative Commons Attribution Non Commercial (CC BY-NC 4.0) license, which permits others to distribute, remix, adapt, build upon this work non-commercially, and license their derivative works on different terms, provided the original work is properly cited, appropriate credit is given, any changes made indicated, and the use is non-commercial. See: http://creativecommons.org/licenses/by-nc/4.0/.

\section{ORCID iDs}

Borja Muniz-Pardos http://orcid.org/0000-0002-9191-9033

Konstantinos Angeloudis http://orcid.org/0000-0002-2417-6612

Kumpei Tanisawa http://orcid.org/0000-0002-9334-7104

Yuri Hosokawa http://orcid.org/0000-0001-9138-5361

Garrett I Ash http://orcid.org/0000-0002-8655-7525

Wolfgang Schobersberger http://orcid.org/0000-0002-5657-0307

Andrew J Grundstein http://orcid.org/0000-0002-0574-6253

Fumihiro Yamasawa http://orcid.org/0000-0001-6315-8479

Sebastien Racinais http://orcid.org/0000-0003-0348-4744

Douglas J Casa http://orcid.org/0000-0002-8858-2636

Yannis P Pitsiladis http://orcid.org/0000-0001-6210-2449

\section{REFERENCES}

1 Kakamu T, Wada K, Smith DR, et al. Preventing heat illness in the anticipated hot climate of the Tokyo 2020 summer Olympic Games. Environ Health Prev Med 2017;22:68.

2 Weather in agosto 2020 in Tokyo, Japan. Available: https://www. timeanddate.com/weather/japan/tokyo/historic?month=8\&year= 2020 [Accessed 29 Sep 2020].

3 Hayashida K, Shimizu K, Yokota H. Severe heatwave in Japan. Acute Med Surg 2019;6:206-7.

4 Enomoto T, Hoskins BJ, Matsuda Y. The formation mechanism of the Bonin high in August. Q J R Meteorol Soc 2003;129:157-78.

5 Meehl GA, Tebaldi C. More intense, more frequent, and longer lasting heat waves in the 21st century. Science 2004;305:994-7.

6 Hosokawa Y, Grundstein AJ, Casa DJ. Extreme heat considerations in international football venues: the utility of Climatologic data in decision making. J Ath/ Train 2018;53:860-5 
7 Tokyo 2020: Next year's Games in numbers. Available: https:// tokyo2020.org/en/news/tokyo-2020-next-year-s-games-in-numbers [Accessed 19 Mar 2021].

8 de Freitas CR, Scott D, McBoyle G. A second generation climate index for tourism (CIT): specification and verification. Int $J$ Biometeorol 2008;52:399-407.

9 Vanos JK, Thomas WM, Grundstein AJ, et al. A multi-scalar climatological analysis in preparation for extreme heat at the Tokyo 2020 Olympic and Paralympic Games. Temperature 2020;7:191-214.

10 Vanos JK, Kosaka E, lida A, et al. Planning for spectator thermal comfort and health in the face of extreme heat: the Tokyo 2020 Olympic Marathons. Sci Total Environ 2019;657:904-17.

11 Casa DJ, DeMartini JK, Bergeron MF, et al. National athletic trainers' association position statement: exertional heat illnesses. J Athl Train 2015;50:986-1000.

12 Racinais S, Casa D, Brocherie F, et al. Translating science into practice: the perspective of the Doha 2019 IAAF world Championships in the heat. Front Sports Act Living 2019;1:39.

13 Casa DJ, McDermott BP, Lee EC, et al. Cold water immersion: the gold standard for exertional heatstroke treatment. Exerc Sport Sci Rev 2007;35:141-9.

14 Notley SR, Flouris AD, Kenny GP. On the use of wearable physiological monitors to assess heat strain during occupational heat stress. Appl Physiol Nutr Metab 2018;43:869-81.

15 Adams WM, Hosokawa Y, Casa DJ. The timing of exertional heat stroke survival starts prior to collapse. Curr Sports Med Rep 2015;14:273-4.

16 Bongers CCWG, Thijssen DHJ, Veltmeijer MTW, et al. Precooling and percooling (cooling during exercise) both improve performance in the heat: a meta-analytical review. Br J Sports Med 2015;49:377-84.

17 Wohlfert TM, Miller KC. Precooling, exertional heatstroke risk factors, and postexercise cooling rates. Aerosp Med Hum Perform 2019:90:12-17.

18 Galloway SD, Maughan RJ. Effects of ambient temperature on the capacity to perform prolonged cycle exercise in man. Med Sci Sports Exerc 1997;29:1240-9.

19 Périard JD, Racinais S, Sawka MN. Adaptations and mechanisms of human heat acclimation: applications for competitive athletes and sports. Scand J Med Sci Sports 2015;25 Suppl 1:20-38.

20 Cheung SS, Sleivert GG. Multiple triggers for hyperthermic fatigue and exhaustion. Exerc Sport Sci Rev 2004;32:100-6.

21 Bongers CCWG, de Korte JQ, Eijsvogels T. Infographic. keep it cool and beat the heat: cooling strategies for exercise in hot and humid conditions. Br J Sports Med 2020. doi:10.1136/ bjsports-2020-102294. [Epub ahead of print: 19 Jun 2020].

22 Arngrïmsson SA, Petitt DS, Stueck MG, et al. Cooling vest worn during active warm-up improves $5-\mathrm{km}$ run performance in the heat. $J$ Appl Physiol 2004;96:1867-74.

23 Taylor L, Carter S, Stellingwerff T. Cooling at Tokyo 2020: the why and how for endurance and team sport athletes. Br J Sports Med 2020;54:1243-5.

24 Périard JD, Racinais S, Timpka T, et al. Strategies and factors associated with preparing for competing in the heat: a cohort study at the 2015 IAAF world athletics Championships. Br J Sports Med 2017;51:264-70.

25 Racinais S, Ihsan M, Taylor L, et al. Hydration and cooling in elite athletes: relationship with performance, body mass loss and body temperatures during the Doha 2019 IAAF world athletics Championships. Br J Sports Med 2021. doi:10.1136/ bjsports-2020-103613. [Epub ahead of print: 12 Feb 2021].

26 Pimental NA, Cosimini HM, Sawka MN, et al. Effectiveness of an air-cooled vest using selected air temperature and humidity combinations. Aviat Space Environ Med 1987;58:119-24.

27 Shapiro Y, Pandolf KB, Sawka MN, et al. Auxiliary cooling: comparison of air-cooled vs. water-cooled vests in hot-dry and hotwet environments. Aviat Space Environ Med 1982;53:785-9.

28 McLellan TM, Frim J, Bell DG. Efficacy of air and liquid cooling during light and heavy exercise while wearing NBC clothing. Aviat Space Environ Med 1999;70:802-11.

29 Jetté FX, Dionne JP, Rose J, et al. Effect of thermal manikin surface temperature on the performance of personal cooling systems. Eur $J$ Appl Physiol 2004;92:669-72.

30 Bennett BL, Hagan RD, Huey KA, et al. Comparison of two cool vests on heat-strain reduction while wearing a firefighting ensemble. Eur J Appl Physiol Occup Physiol 1995;70:322-8.

31 Carter JM, Rayson MP, Wilkinson DM, et al. Strategies to combat heat strain during and after firefighting. J Therm Biol 2007;32:109-16.

32 Chou C, Tochihara Y, Kim T. Physiological and subjective responses to cooling devices on firefighting protective clothing. Eur J Appl Physiol 2008;104:369-74.
33 Tyler CJ, Sunderland C, Cheung SS. The effect of cooling prior to and during exercise on exercise performance and capacity in the heat: a meta-analysis. Br J Sports Med 2015;49:7-13.

34 Adams WM, Hosokawa Y, Casa DJ. Body-cooling paradigm in sport: maximizing safety and performance during competition. J Sport Rehabil 2016;25:382-94.

35 Luomala MJ, Oksa J, Salmi JA, et al. Adding a cooling vest during cycling improves performance in warm and humid conditions. $J$ Therm Biol 2012;37:47-55.

36 Ruddock A, Robbins B, Tew G, et al. Practical cooling strategies during continuous exercise in hot environments: a systematic review and meta-analysis. Sports Med 2017;47:517-32.

37 Schlicht E, Caruso R, Denby K, et al. Effects of wrist cooling on recovery from exercise-induced heat stress with Firefighting personal protective equipment. J Occup Environ Med 2018;60:1049-00.

38 The National. Wearable air conditioners are here: the Reon pocket can lower your temperature by 13 degrees Celsius. Available: https://www.thenationalnews.com/arts-culture/wearableair-conditioners-are-here-the-reon-pocket-can-lower-yourtemperature-by-13-degrees-celsius-1.1055119 [Accessed 1 Nov 2020].

39 Japan Trend Shop. Neck cooler mini. Available: https://www. japantrendshop.com/ES-neck-cooler-mini-p-4971.html [Accessed 10 Dec 2020].

40 ExtremeTech. Wristify: a personal Peltier wrist cooler that could save the US millions in energy costs. Available: https://www. extremetech.com/extreme/169951-wristify-a-personal-peltier-wristcooler-that-could-save-the-us-millions-in-energy-costs [Accessed 10 Dec 2020].

41 Yu X, Li Y, Wang X, et al. Thermoconductive, Moisture-Permeable, and Superhydrophobic nanofibrous membranes with Interpenetrated boron nitride network for personal cooling fabrics. ACS Appl Mater Interfaces 2020;12:32078-89.

42 Belval LN, Casa DJ, Adams WM, et al. Consensus Statementprehospital care of exertional heat stroke. Prehosp Emerg Care 2018;22:392-7.

43 O'Brien C, Hoyt RW, Buller MJ, et al. Telemetry pill measurement of core temperature in humans during active heating and cooling. Med Sci Sports Exerc 1998;30:468-72.

44 Muniz-Pardos B, Sutehall S, Angeloudis K, et al. The use of technology to protect the health of athletes during sporting competitions in the heat. Front Sports Act Living 2019;1:38.

45 Düking P, Stammel C, Sperlich B, et al. Necessary steps to accelerate the integration of wearable sensors into Recreation and competitive sports. Curr Sports Med Rep 2018;17:178-82.

46 Muniz-Pardos B, Sutehall S, Gellaerts J, et al. Integration of wearable sensors into the evaluation of running economy and foot mechanics in elite runners. Curr Sports Med Rep 2018;17:480-8.

47 Peake JM, Kerr G, Sullivan JP. A critical review of consumer Wearables, mobile applications, and equipment for providing biofeedback, monitoring stress, and sleep in physically active populations. Front Physiol 2018;9:743.

48 Muniz-Pardos B, Sutehall S, Angeloudis K, et al. Recent improvements in marathon run times are likely technological, not physiological. Sports Med 2021;51:371-8.

49 Bongers CCWG, Daanen HAM, Bogerd CP, et al. Validity, reliability, and inertia of four different temperature capsule systems. Med Sci Sports Exerc 2018;50:169-75.

50 World Athletics. Competition and technical rules, 2020. Available: https://www.worldathletics.org/download/download?filename= 0400178d-ce56-43ff-aa9c-6b4433aafcea.pdf\&urlslug=Competition \%26 Technical Rules

51 International Olympic Committee. IOC policy regarding certain NOC scientific and medical equipment for the games of the XXXII Olympiad in Tokyo in 2020, 2020. Available: https://stillmedab. olympic.org/media/Document Library/OlympicOrg/Games/SummerGames/Games-Tokyo-2020-Olympic-Games/IOCPolicyRegardingCe rtainNOCScientificandMedicalEquipmentfortheGamesoftheXXXIIOI ympiadinTokyo.pdf?la=en\&hash=8F5DC05C9988DB58E265907D ODA528B [Accessed 6 Jan 2021].

52 World Athletics. Technical rules, 2019. Available: https://www. worldathletics. $\mathrm{rg} /$ download/download?filename=febae412-b6734523-8321-e1ed092421dc.pdf\&urlslug=C2.1

53 The Guardian. Marathon experts condemn delay in treatment to collapsed Callum Hawkins. Available: https://www.theguardian.com/ sport/2018/apr/15/marathon-greats-condemn-games-organisersover-hawkins-treatment [Accessed 12 Jun 2019].

54 Taylor L, Thornton HR, Lumley N, et al. Alterations in core temperature during World Rugby Sevens Series tournaments in temperate and warm environments ${ }^{\dagger}$. Eur $J$ Sport Sci 2019;19:432-41. 
55 Racinais S, Moussay S, Nichols D, et al. Core temperature up to $41.5^{\circ} \mathrm{C}$ during the $\mathrm{UCl}$ road cycling world Championships in the heat. Br J Sports Med 2019;53:426-9.
56 Heat illness prevention information provided by Ministry of the environment. Available: https://www.wbgt.env.go.jp/en/ [Accessed 28 Dec 2020]. 